\title{
Smart technology for self-organizing processes
}

\author{
Marlene Scardamalia* and Carl Bereiter
}

\author{
* Correspondence: \\ marlene.scardamalia@utoronto.ca \\ Institute for Knowledge Innovation \\ and Technology, University of \\ Toronto, Toronto, Canada
}

\begin{abstract}
Learning technology periodically undergoes changes in response to changes in the prevailing models of human cognition and learning. A major shift throughout the behavioral sciences that began in the 1980s is beginning to have effects at the level of classroom learning and its supportive technologies. Inspired by complexity theory, it is a shift that treats all learning and knowledge building as essentially self-organizing processes. The design challenge is not to control the self-organizing process, as some instructional approaches attempt to do, but to facilitate the emergence of higher-level outcomes-e.g., better explanations, more coherent understanding. To foster such higher-level emergents, smart technologies not only need to support people interacting productively with other people but also ideas interacting productively with ideas and feedback systems promoting engagement between people and ideas. This is in contrast to conceptions of smart technology that see it as providing increasingly precise centralized control over learning processes. Smart technology attuned to the emergent character of learning and thinking does not simply turn more control over to the learners but shifts the emphasis from control to productive interaction among learners, teachers, ideas, and technology.
\end{abstract}

Keywords: Centralized mindset; Knowledge building; Self-organization; Complexity theory; Design thinking

We started developing educational technology in 1983, at a time when cognitivelyoriented technology was exploiting what was seen as a natural affinity between the mind's logic engine and that of the computer. However, we resisted the temptations of artificial intelligence, expert systems, and instructional management systems, focusing instead on students as epistemic agents in learning. As we put it then,

At first thought it might seem that the key requirement is a highly intelligent tutoring system, capable of performing sophisticated diagnoses of students' learning strategies, providing sensitive coaching and instruction. Such a system, however, is not only unrealistic, given the state of the art; it may also be heading in the wrong direction ... For it is not the computer that should be doing the diagnosing, the goal-setting, and the planning, it is the student. The computer environment should not be providing the knowledge and intelligence to guide learning, it should be providing the facilitating structure and tools that enable students to make maximum use of their own intelligence and knowledge (Scardamalia et al. 1989), p. 54.

The technology we developed was originally focused on support of intentional learning in a networked social environment-hence the name "Computer-Supported Intentional

(c) 2014 Scardamalia and Bereiter; licensee Springer. This is an Open Access article distributed under the terms of the Creative Commons Attribution License (http://creativecommons.org/licenses/by/4.0), which permits unrestricted use, distribution, and reproduction in any medium, provided the original work is properly credited. 
Learning Environment" or "CSILE". However, we quickly recognized that the young students using CSILE were doing more than helping each other learn. They were in fact engaged in a collective process that in the business world was coming to be called "knowledge creation" (Nonaka \& Takeuchi 1995) but which we had already labeled "Knowledge Building" (Scardamalia et al. 1994) - a collaborative effort to advance the state of knowledge and ideas in a community. As discussed elsewhere (Bereiter \& Scardamalia 2014), the terms knowledge building/knowledge creation are basically interchangeable. Knowledge Building pedagogy, however, deals with the particular issues of pursuing knowledge creation in an educational context. CSILE and its successor, "Knowledge Forum", with more powerful supports for collaborative Knowledge Building, became part of a larger movement in the learning sciences undergirded by sociocultural theory (John-Steiner \& Mahn 1996), realized at a practical level in Computer Supported Collaborative Learning (CSCL), and highlighted by such concepts as "situated learning" (Lave \& Wenger 1991) and "group cognition (Stahl 2006).

In the meantime, a revolution has been taking place in the behavioral sciences. Its origins are in the 1980s, when two important advances in the behavioral sciences took place. One was research on mental models, which produced evidence that the mind does not function like a logic machine after all but more like a simulation device (Johnson-Laird 1983; Johnson 2009). The other was the development of connectionism, which demonstrated how complex adaptive structures can function without the executive control that intelligent systems had been assumed to require (Molenaar 1986). Later, complexity theory (Kauffman 1995) provided a coherent basis for both mental models and the emergent cognitive structures. Under this broad theoretical umbrella, single-factor or multifactorial explanations of everything from motor skills to the rise and collapse of civilizations are giving way to systemic explanations in which outcomes are seen as emergents of self-organizing processes among lower-order components. Learning and human development in general call for systemic explanations (Thelen \& Smith 1994). The concept of self-organization, which now plays an essential role in explaining the evolution of complex novel biological structures (Dawkins 1987), also offers a solution to what Piaget (1971) recognized as the ultimate problem for genetic epistemology: "How can one attain to something new?" But complexity theory's role in education has been almost entirely theoretical (Bereiter \& Scardamalia 2013). Since self-organization characterizes learning of all kinds, from the most highly regulated to the most spontaneous, complexity theory cannot help resolve the endless controversies about how best to promote learning. But complexity theory ought at least to have implications for the design of educational technologies. Our purpose in this paper is to explore such implications.

\section{Technology attuned to the self-organizing character of learning and thought}

Learning technology attuned to the self-organizing character of learning and thought does not necessarily have to function in a self-organizing manner itself. However, smart educational technology of the future may well do so and thus be able to interact with students in a self-organizing system where neither one controls the other. There is already network analysis technology that situates people and words in the same Euclidian space with emergent properties (Oshima et al. 2012). This is in contrast to rule-based smart technology, which dominated artificial intelligence in its early decades (cf. Anderson 1993). 
The distinctive nature of the design challenge implicit in the self-organizing character of individual and group cognition may be brought to a more concrete level by considering two formulations of the goal of improving students' thinking-a goal much in evidence in current concerns with innovativeness. One popular formulation, dating from research of the 1950s, is "teach them thinking skills"; the other, dating from much farther back, is "help them become thinking persons". In the current literature of " $21^{\text {st }}$ century skills" programs no distinction is made. Although the long-range goal of such programs is people who think in the creative and critical ways required by citizenship and work in a knowledge-based society, the immediate goal is measurable gains on tests of specific skills. The implicit assumption is that the long-range objective cannot be pursued directly during the formative years. The alternative formulation, which implicitly denies this assumption, is vividly expressed in a frequently quoted passage attributed to Bertrand Russell:

When you want to teach children to think, you begin by treating them seriously when they are little, giving them responsibilities, talking to them candidly, providing privacy and solitude for them, and making them readers and thinkers of significant thoughts from the beginning. That's if you want to teach them to think. (Emphasis added.)

There is no mention of skill teaching here. Russell treated "teach them to think" as a matter of enculturating students into the society of "thinkers of significant thoughts". This was to be accomplished by arranging experiences and conditions and, most strikingly, treating children as already junior members of this society of thinkers rather than as trainees.

To the learning technologist, a mandate to "teach thinking skills" immediately brings to mind such functions as presenting problems, teaching reasoning and problem solving strategies, managing inquiry projects, scripting argumentation, tagging items for alignment with curriculum goals, and so forth. By contrast, a mandate to help students develop into "thinkers of significant thoughts" may not immediately bring to mind anything in particular beyond what is already available in an information-rich classroom. Further reflection, however, suggests a number of definite challenges for technology designed for helping learners develop into thinkers:

- Higher levels of agency for students (Scardamalia \& Bereiter 1991): turning over to the learners strategic cognitive activity normally confined to the teacher-e.g., priority setting, evaluating progress, trouble-shooting, ensuring inclusiveness.

- Promoting collective cognitive responsibility: students functioning like expert teams that go beyond division of labor to making every member responsible for doing whatever is necessary to achieve success in a joint effort (Scardamalia 2002).

- Democratizing knowledge and knowledge-building activity.

- Identifying and discussing promising ideas: determining which ideas are most worthy of further work.

- Explanation-building discourse (Bereiter 2012): distinct from argumentation and guided by principles of explanatory coherence.

- Metacognitive judgment: evaluating the progress of knowledge-building or problem-solving discourse, critically examining goals, finding ways around obstacles. 
- Giving ideas a life of their own: School practices and social media both tend to personalize ideas, which is fine at an early stage of idea development; but at some point ideas should become detached from their authors and open to criticism and revision by the whole community without its reflecting on the authors.

- Support for tentativeness and risk-taking with ideas.

These are essentially the specifications we have set out elsewhere for knowledge building environments (Scardamalia 2003; Scardamalia \& Bereiter 2006, in press-b).

\section{Support for knowledge building discourse: not too little, not too much}

Simulations, handy laboratory instruments, robotics, immersive digital environments, technologies that enable students to create movies, games, and now (with 3D printing) physical working models-all these can provide valuable support for knowledge building, but community knowledge building requires that outputs from such sources become objects for group discourse and continuing discovery. In the end collaborative knowledge building rises or fails on the success of that discourse in generating knowledge advances. The central role of discourse has also been recognized in the literature of organizational knowledge creation (von Krogh et al. 2000; Tsoukas 2009).

Any communication technology can be a medium for knowledge building discourse as long as it enables people to represent and preserve ideas in a form comprehensible to others and allows for discussion and revision. But this presupposes a community of users already skilled and committed to knowledge building discourse. Education's challenge is getting students up to that level, and for this communication technology could benefit considerably from improved design. Some of it offers so little help that discourse will persist at a low epistemic level. Some of it controls the discourse so much that it affords the users little opportunity to acquire the goal-setting and planning skills needed for them to become active participants in a knowledge building community. Even for quite sophisticated knowledge builders common varieties of discourse technology make collaborative "integrative thinking" (Martin 2009) unnecessarily awkward and inefficient. Technology that does too little to support knowledge building discourse is represented by the ubiquitous threaded discussion. Technology that takes over too much of what students should be learning to do themselves is represented by the more extreme forms of what Dillenbourg and Jermann (2006) called "micro-scripting". Along the continuum from too little to too much we find the following:

\section{Threaded discourse: ICT's version of the message in the bottle}

Technology for asynchronous online discourse has not changed much since the 1990s. It still consists of notes arranged in chronological order, with appended comments, comments on comments, and so on in what usually turns out to be a short chain of indentations. Idea revision is hampered by notes and comments getting lost in strings of messages. Synthesis of ideas into more complex structures is hampered by the fact that only subordination is supported (adding notes under existing notes) and not superordination (introducing a note that stands above and draws together or is supported or elaborated by a set of existing notes). "Integrative thinking", defined by Martin (2009) as holding "two conflicting ideas in constructive tension", is impeded by the inability to link to two different notes or to link across different discourse threads. Other 
technology allows for tagging, grouping, and flexible rearrangement. The challenge, however, is to combine such activity with focus on big ideas, synthesis, and breakthroughs. The common variety of threaded discourse is adequate for question-answer and opinion-reaction exchanges, and these constitute almost the whole of what one finds in the ubiquitous threaded discussions attached to news stories and blog postings on the web. But for people trying to carry on serious constructive work with ideas, threaded discourse technology is a source of continual frustration. Like setting messages afloat in bottles, threaded discourse has the virtue of preserving ideas and getting them out into the world, but is not a good way of getting them to a desired destination or for maintaining a productive exchange. Instructional management systems have started claiming to be collaborative. What this apparently means, however, is that they have handy mechanisms for creating groups. This is a useful capability, especially with thousands of scattered students taking the same online course, but instructional management systems persist in a use of discourse technology that limits possibilities for knowledge building discourse.

\section{Scripts: good idea, wrong context}

It would be unfair to say that educational ICT has not gone beyond threaded discourse. It has gone far beyond it, perhaps too far. It has gone beyond enhancing the kind of ideational discourse people normally carry on orally and replaced it with discourse carried out according to scripts (Fischer et al. 2013). The term "script", as used in current instructional research, is derived from its use by Schank and Abelson (1977) in describing frequently experienced social routines such as dining in a restaurant. The principal elements are roles (e.g., head waiter, waiter, customer) and conventional behaviors associated with the roles (e.g., being shown to a table by the head waiter, asking the waiter for the bill at the end of the meal). These elements continue to dominate scripted instruction, in which assigned roles are common and the scripts prescribe behavioral sequences tied to roles. Such scripts stand in contrast to the emergent character of much human action, including practically everything that would come under the headings of meaningful learning and creative thinking. These often take place within a script framework (for instance, the academic colloquium, which has defined roles and ritualized behavior) but the essence of the activity (for instance, arriving at a theoretical explanation of puzzling data) is invariably emergent and unscripted. Thus the extension of the script concept not just to the outward forms of classroom life (which are often highly ritualized) but to the cognitive and socio-cognitive processes of work with concepts and ideas is an extraordinary leap. The power of the script idea as developed by Schank and Abelson lay in recognizing and describing the more ossified forms of social behavior, the ones where emergence is minimized and predictability is maximized. Scripts offer a good model when applied to a suitable objective, such as learning the etiquette of an unfamiliar culture, but a bad model likely to defeat the purpose when applied to constructive work with concepts and ideas, where emergence is maximized and unpredictability is inherent.

\section{Confusing performance supports with learning supports}

Educational technologists are generally well aware of the difference between performance support and learning support and recognize that what is optimal for one is not 
necessarily optimal or even beneficial for the other. A spelling checker is an obvious and widely accepted performance support for writing, but what is its effect on learning to spell? It might promote it, interfere with it, or render it unnecessary. The three possibilities have been debated for years, with inconclusive evidence supporting each position. The same has happened with regard to hand-held calculators in elementary mathematics instruction. But with more complex technology, the performance-learning issue becomes less clear-cut. Scripts, suggesting and reminding systems, and the like are clearly performance supports, but their use in education carries with it the supposition that they also support learning. This is especially apparent in workplace training, and may be appropriate there, when there is a "right way" to do something and performance supports guide the learner through doing it the right way. But when the challenge is self-organizing systems for emergence of increasingly high-level knowledge, reliance on performance supports as learning supports is more questionable. Script researchers talk about "internal scripts" as the student's internalization of the "external script" used in instruction. The implicit assumption is that the scripts represent not only a type of performance support but also the procedural knowledge learners are supposed to acquire and take away from the scripted activity. Hesse (2007) has listed five reasons, which we paraphrase here, for questioning whether scripting the "right way" of carrying out a collaborative task is a sound way of managing learning:

- The "right way" may be wrong.

- The "right way" may be different for different persons and situations.

- The "right way" may only be good advice at an early stage.

- The "right way" may be demotivating.

- The "right way" may increase cognitive load and so diminish attention to goals.

Research on a variety of academic skills indicates that strategy instruction improves performance, but seldom does the research investigate whether students actually use the taught strategies. Effects could be of a more global nature, for instance through fostering mindful engagement (Salomon \& Globerson 1987). The stronger the strategy guidance provided by the technology, the more critical it becomes that these strategies constitute the "right way" for everyone. Seldom if ever is this requirement seriously investigated. What we know from biographies of major writers and scientists suggests there is no best way of productive thinking that should be imposed on learners.

\section{Technology that supports working with ideas in "Design Mode"}

Working constructively with ideas involves building something out of ideas-an explanation, a model, an elaboration or improvement of an idea. It means treating conceptual work as knowledge creation rather than simply knowledge acquisition. This calls for a major reorientation of approach to ideas, a switch from what we have labeled "belief mode" to "design mode" (Bereiter \& Scardamalia 2003). The term "belief mode" is derived from the traditional definition of knowledge as "true and justified belief". It includes all the many ways of advancing and evaluating knowledge claims, from "it's true because the textbook says so" to "the weight of evidence indicates" and beyond that to "from this perspective...." Design mode, by contrast, is the mode of invention, theory building, solving real complex problems with no ready-made solutions, identifying and 
exploiting promising ideas. A related term is "design thinking", originally referring to kinds of thinking promoted in design schools and architecture schools, but subsequently expanded to a kind of thinking applicable to complex problems of all kinds (Buchanan 1992). Design mode is more concerned with whether an idea has potential than whether it is "true and justified" in its present form, and so the preferred discourse form is not pro-con argumentation but collaborative problem solving.

Technology for work in belief mode is abundant, especially in the form of software for argumentation (Andriessen et al. 2003). Work in belief mode lends itself to scripted procedures: There are accepted procedures for hypothesis testing (often presented as "the scientific method") and models of rational argument, an enduringly popular one being that of Toulmin (1958). The same is not true of work in design mode. There are not established forms and procedures for treating ideas in design mode, and efforts to establish them would be resisted for good reason. However, smart classrooms are evolving in ways that can support creative work with ideas. These include affordances for real-time interactivity, complex adaptive approaches, and ubiquitous learning (Huang et al. 2012; Kinshuk et al. 2010; Kinshuk \& Graf 2012; Norris \& Soloway 2013). The same affordances can also be used to strengthen centralized control and to promote activity in belief mode, however, so it is important for practitioners and designers to have a clear conception of creative knowledge work as an objective.

The one characteristic of design thinking that is widely accepted and applicable to all situations is that design is an iterative process of idea testing and improvement. "Improvable ideas" is a core concept of Knowledge Building (Scardamalia 2002). As suggested by Hakkarainen's cyclical Progressive Inquiry model (Muukkonen et al. 1999), Knowledge Building involves transformational changes not only in knowledge but also in problem definition. These in turn lead to "theory" changes and further design iterations.

From our earliest days of designing knowledge-building technology, our focus has been on enabling students to work effectively in design mode. Initially this consisted mainly of providing epistemic markers for design mode activities such as theory building: hence, providing phrases such as "My theory...," "This theory does not explain...," and "A better theory..." that users could click on to incorporate into their note texts. We encourage customization and actively discourage mandated use or set sequences. More recent technological enhancements facilitate the identification and discussion of promising ideas (Chen et al. 2012) and metadiscourse-discourse about the progress and problems of the main knowledge-building discourse. Such metadiscourse is aided by a variety of feedback tools that, for instance, map the community's use of theorybuilding markers or compare the community's vocabulary usage on a particular topic with the vocabulary in a related "expert" corpus (Resendes 2013). Developing ways to support sustained creative work with ideas is an ongoing effort, however. On the horizon are dynamic 3-D visualizations showing the self-organizing process of constructing higher-level complex ideas out of simpler lower-level ones (Tergan \& Keller in press).

Further development of technology to support working with ideas in design mode would clearly be a boon to innovation-driven businesses, but it could have a revolutionary impact on education, where both traditional knowledge-transmission and modern inquiry-oriented approaches have focused almost exclusively on activity in belief mode. The emphasis needs to be not simply on creative thinking but on sustained creative thought. "Ideas are the easy part", says design group Fahrenheit 212 (2009). By this they 
mean initial bright ideas, of the kind often generated through brainstorming. Initial bright ideas are usually in ample supply both in innovation-minded companies and in classrooms. The hard part is developing initial bright ideas into something of value, be it a merchantable product or a contribution to knowledge. This is design. It is creative work, sometimes at a higher level than what produced the original idea, and it is the essence of Knowledge Building.

Because of their shared conceptual basis, there ought to be considerable crossfertilization between technology for knowledge creation in industry and technology for knowledge building in education. Customarily, technology transfer works in only one direction-from business applications to educational ones. But in a knowledge creation/knowledge building context transfer could work both ways. The seven design challenges listed earlier (higher levels of agency, and so on) are vital when the goal is the educational one of developing students into productive thinkers. They are all relevant to the success of knowledge-creating and design teams in industry, but they do not typically receive technological support. The knowledge management literature suggests these sorts of socio-cognitive conditions are the responsibility of managers. But technology that provides the necessary support for novice knowledge creators has, in our experience, proved helpful for adult knowledge workers as well, especially those who are not yet at the point where collaborative knowledge creation comes naturally. Important for students and experienced knowledge workers alike is a context that encourages collective cognitive responsibility (Scardamalia 2002). A well-designed digital community workspace can do that.

To support collective cognitive responsibility in work with ideas, digital tools need to function at two levels: (1) the creation of a rich, interconnected network of ideas in the community's knowledge space and (2) higher-level views of group processes and the resulting knowledge products so as to enable evaluation of progress and determination of future moves. At the first level, users create connections: referencing, annotating and keywording notes, adding epistemic markers, highlighting promising ideas. Activities at the second level may take a variety of forms, which might include viewing near- and far- conceptual neighbors, compiling promising ideas in a content area, judging rate of conceptual progress as indicated by the presence of new concepts, and recognizing outliers-both people and ideas. The result should be an ever-evolving conceptual space, providing feedback to ongoing creative discourse, enabling each member to be part of the collective achievement.

\section{Nurturing the emergence of new competencies}

In the almost universal top-down approach to curriculum design and standards setting, experts and stakeholders determine the knowledge and skills to be acquired. These are translated into tests, instructional procedures, and learning activities. Teachers then implement them with students, who usually have no idea of the origins and rationale of the goals or the procedures nor any way to contribute to or refine them. This traditional curriculum approach continues to prevail even in such supposedly leading-edge initiatives as the " $21^{\text {st }}$ century skills" movement (Johnson 2009). Business executives, psychometricians, and educationists get together and agree on a list of skills needed for the $21^{\text {st }}$ century (which bear a striking resemblance to the "higher-order skills" promoted throughout the previous 50 years). Then tests are constructed and curriculum 
developers are enlisted to prescribe procedures for developing the listed skills. However, in a report prepared for one of these $21^{\text {st }}$ century skill projects, Scardamalia et al. (2012) argued that in a project with such forward-looking aspirations the traditional working-backward-from-goals approach ought to be augmented by provisions for the discovery of new needed competencies, rather than supposing that these can all be identified in advance. In order to discover new competencies, however, there need to be educational environments in which new competencies have a chance to emerge. The authors proposed a systemic approach containing various feedback loops enabling qualitative and not just quantitative shifts at all levels of the policy-maker to practitioner to learner hierarchy. In the traditional top-down system, the task of learning technology is to help enact the decisions made at higher levels in the system. In a dynamic systems approach, the job of technology is multifarious but overall it should promote self-organizing evolutionary processes in all parts of the education system, processes that moreover interact with each other to achieve coherent progressive development.

Technology able to do this would have to be very smart indeed, but not smart in a controlling fashion. Feedback mechanisms are key, but the feedback itself must be able to evolve to deal not only with emerging problems but also with emerging opportunities. The latter is more challenging. Trouble-shooting-detecting when things are going wrong and finding out why-is common in all kinds of enterprises, including education systems, but detecting and exploring opportunities is much less common, is the province of adventurous artists, designers, and entrepreneurs, and is virtually unknown in education. We do not suggest that some monster application is required that integrates all aspects of the educational process. Learning analytics (Siemens \& Long 2011), a discipline still in its formative stages, appears to be relished by some as a way of creating such an application but by others as a means of decentralizing control, making information more usable by teachers and students. Technology for opportunityfinding and exploration needs to start at the level of the classroom (we use that term to refer to any social environment organized for an educational purpose, recognizing that the "classroom" might be an after-hours club, a dispersed group of online learners, a museum exhibit, and so forth). That is where the opportunities will first emerge for going beyond "best practice" and the goals established by policy-makers.

\section{Conclusion: toward 2025 in educational technology}

The year 2025 or thereabout has become the focus of much visionary talk in education, spurred on by several major foundations and education reform groups that have selected some target year a decade or two out by which their education reform goals are to be achieved. What the surrounding society and especially the technological infrastructure will be like by 2025 is of course very difficult to predict, given the rate of change. However, in broad strokes we can with some confidence paint a picture in which computers are considerably more intelligent than today and have automated a number of human activities, including mental ones, that they can do better or at least more economically than we can. This prospect has led many educators to conclude that education for the future must focus on cultivating creativity, believed to be the last bastion of human superiority over the machine. However, if by creativity we mean the sorts of things taught in creativity workshops, that last bastion will probably not hold 
either. Generating novel ideas meeting defined constraints is something computers of the future ought to be able to do with ease, generating more ideas that meet more constraints than human intelligence can match.

Much alarmist commentary on the web reflects a mindset occupied with Humpty Dumpty's question, "Which is to be master?" One of the most authoritative pronouncements on the subject (Hawking et al. 2014) warns, "Whereas the short-term impact of AI depends on who controls it, the long-term impact depends on whether it can be controlled at all." If we adopt a systems view, however, the design task is not to ensure the continuance of human control or to find a safe niche for human talent. It is to facilitate human-machine collaboration.

In education, facilitating human-machine collaboration means designing technology and ways of using it that integrate it into a complex system in which the principal interacting elements are students, teachers, intelligent machines, and ideas. As we have proposed here, the principal medium for such interaction is dialogue. Smart phones are already demonstrating that dialogue between person and machine is possible within fairly generous limits, and those limits are likely to be extended greatly. In work reported by Miyake et al. (2011), children carry on discussion with each other and with a robot (voiced and controlled by an assistant in another room, preliminary to having a robot able to carry on scripted conversation). Latent semantic analysis (Landauer \& Dumais 1997) and explanatory coherence analysis (Thagard 2000) demonstrate that ideas can interact computationally with ideas in ways that produce meaningful emergent structures. Learning analytics, which enable the computer to discover patterns in unstructured data that are beyond human capacity, are developing in a variety of ways. Some applications raise the spectre of increasing centralized control (Yuan n.d.), but others such as diagnostic analyses and "recommender systems" that suggest resources students might find useful or interesting (Manouselis et al. 2012) could play positive roles in a self-organizing educational process.

All of this inevitably raises question about the role of teachers. One answer lies in the importance of a classroom culture conducive to sustained creative work with ideas (Scardamalia \& Bereiter 1996). With any interacting group of students a social organization of some kind will emerge, but it will not necessarily or even very likely be organized around the pursuit of knowledge and understanding. It may be organized around assigned tasks, topical interests, or in the worst cases organized around combatstudents against the teacher or students against each other. Teachers we have worked with over the years consistently report that creating a knowledge building culture takes time and effort and that it needs continuing attention. But it would be a mistake to view such community building as a task separate from actual work with ideas. A community organized around knowledge building can be compared to a community organized around agricultural production. Not everything that goes on in a farm community is actual farming but everything is in some manner tied to it and the community thrives or declines on the basis of its production of marketable food. In the same way, a knowledge building community thrives or declines on the basis of its production of valuable knowledge. For such a community to develop, knowledge building has to be at the center of the community's development from the beginning.

Organization for knowledge creation and new competencies related to it does not negate or lessen the demand for older well-recognized competencies in literacy, numeracy, and 
subject-matter knowledge. More likely newly identified competencies will add new dimensionality to the traditional ones, as has happened when print literacy was expanded to "multiliteracy" and recently to "transliteracy," which includes not only ability to utilize diverse information sources but to synthesize coherent knowledge from fragmentary information thus obtained (Liu 2012; Scardamalia \& Bereiter in press-a). A great deal of recent educational technology is in aid of learning with understanding. But the proliferation of simulations, instruments, games, construction tools, and the like will not necessarily result in self-organization of understanding for learners. In fact, it may make coherence harder to achieve. There needs to be some glue. The glue nature gave us is discourse. What future smart technology may be able to provide is attractive and effective ways for idea-centered discourse to self-organize around the production of understanding.

Instructional management systems are now being designed to facilitate the forming of collaborative groups. That is a worthwhile start, but such groups need to be infused with an ethos of sustained explanation building, problem deepening, idea improvement, and collective cognitive responsibility. Developing such an ethos is the essence of creating a knowledge building community. It is clearly a task for the human beings involved. Can technology help with this task, or is its value confined to the intellectual and administrative aspects of collaborative work with ideas? Both organization science and cognitive science have taken a decided turn toward including affect, empathy, and interest as components of the knowledge creation process, interacting constructively with the conceptual and logical components rather than working separately to bias and motivate the process (Kunda 1999; Liedtka \& Ogilvie 2011). Thagard, in his theory of emotional coherence (2006), presents a computational model of thought in which ideas, facts, and emotions together form a dynamic network that generates realistic cognitive outcomes. Thus a scientific groundwork is being laid that by 2025 should enable technology that actively collaborates in both the socio-emotional and the intellectual aspects of creative work with ideas. Educational technology designers can begin working toward this end by building into software learning environments semantic tools (Rosé et al. 2008), knowledge visualizations (Marchese \& Banissi 2013), network analyses (Freeman 2004), and other resources that students and teachers can use to provide realtime feedback to their work with ideas. Out of such limited forms of assistance may arise clearer understanding of the competencies and obstacles that more powerful technology will need to address.

Received: 21 February 2014 Accepted: 19 May 2014

Published: 16 October 2014

References

JR Anderson, Rules of the mind (Lawrence Erlbaum Associates, Hillsdale, NJ, 1993)

J Andriessen, M Baker, D Suthers (eds.), Arguing to learn: Confronting cognitions in computer-supported collaborative learning environments (Kluwer, Dordrecht, 2003)

C Bereiter, Theory building and education for understanding, in Encyclopaedia of philosophy of education, ed. by MA Peters, P Ghiraldelli, B Zarnic, A Gibbons, 2012. Web document: http://eepat.net/doku.php?id=theory_building_ and_education_for_understanding

C Bereiter, M Scardamalia, Learning to work creatively with knowledge, in Powerful learning environments. Unraveling basic components and dimensions (pp. 55-68). (Advances in Learning and Instruction Series), ed. by E De Corte, L Verschaffel, N Entwistle, J van Merriënboer (Elsevier Science, Oxford, UK, 2003)

C Bereiter, M Scardamalia, Self-organization in conceptual growth: Practical implications, in International handbook of research on conceptual change, ed. by S Vosniadou, 2nd edn. (Routledge, New York, NY, 2013), pp. 504-519

C Bereiter, M Scardamalia, Knowledge building and knowledge creation: One concept, two hills to climb, in Knowledge creation in education, ed. by SC Tan, HJ So, J Yeo (Springer, Singapore, 2014)

R Buchanan, Wicked problems in design thinking. Design. Issues. 8(2), 5-21 (1992) 
B Chen, M Scardamalia, M Resendes, M Chuy, C Bereiter, Students' intuitive understanding of promisingness and promisingness judgments to facilitate knowledge advancement, in The future of learning: Proceedings of the 10th international conference of the learning sciences (ICLS 2012) -, ed. by J van Aalst, K Thompson, MJ Jacobson, P Reimann. Full Papers, vol. 1 (ISLS, Sydney, Australia, 2012), pp. 111-118

R Dawkins, The blind watchmaker: Why the evidence of evolution reveals a universe without design (Norton, New York, 1987)

P Dillenbourg, P Jermann, Designing integrative scripts, in Scripting computer-supported communication of knowledge Cognitive, computational, and educational perspectives, ed. by F Fischer, I Kollar, H Mandl, J Haake (Springer, New York, 2006), pp. 259-288

Fahrenheit 212, White paper: Ideas are the easy part, 2009. Web: www.strategydriven.com/2010/02/17/ideas-are-theeasy-part

F Fischer, I Kollar, K Stegmann, C Wecker, J Zottmann, Collaboration scripts in computer-supported collaborative learning, in The international handbook of collaborative learning, ed. by CE Hmelo-Silver, AM O'Donnell, CA Chinn, C Chan (Routledge, New York, NY, 2013), pp. 403-419

LC Freeman, The development of social network analysis: A study in the sociology of science (Empirical Press, Vancouver, BC, Canada, 2004)

S Hawking, M Tegmark, S Russell, F Wilczek, Transcending complacency on superintelligent machines. Huffington Post, 2014. www.huffingtonpost.com/2014/05/05/stephen-hawking-artificialintelligence_n_5267481.html

FW Hesse, Discussion: Being told to do something or just being aware of something? An alternative approach to scripting in CSCL, in Scripting computer-supported collaborative learning, ed. by F Fischer, I Kollar, H Mandl, M HaakeJörg, vol. 6 (Springer, Boston, MA, 2007), pp. 91-98

R Huang, Y Hu, G Xiao, The functions of smart classroom in smart learning age, in Proceedings of the 20th International Conference on Computers in Education ICCE 2012 (pp. 413-417), ed. by G Biswas, LH Wong, T Hirashima, W Chen (National Institute of Education, Nanyang Technological University, Singapore, 2012)

P Johnson, The 21 $1^{\text {st }}$ century skills movement. Educ. Leadersh. 67(1), 11-11 (2009)

PN Johnson-Laird, Mental models: Towards a cognitive science of language, inference and consciousness (Cambridge University Press, Cambridge, UK, 1983)

V John-Steiner, H Mahn, Sociocultural approaches to learning and development: A Vygotskian framework. Educ. Psychol. 31, 191-206 (1996)

$S$ Kauffman, At home in the universe: The search for laws of self-organization and complexity (Oxford University Press, New York, 1995)

Kinshuk, S Graf, Ubiquitous learning, in Encyclopedia of the Sciences of Learning, ed. by N Seel (Springer, Berlin, 2012), pp. 3361-3363. ISBN 978-1-4419-1428-6

CM Kinshuk, S Graf, G Yang, Adaptivity and Personalization in Mobile Learning. Technol. Instr. Cogn. Learn. 8(2), 163-174 (2010)

Z Kunda, Social cognition: Making sense of people (MIT Press, Cambridge, MA, 1999)

TK Landauer, ST Dumais, A solution to Plato's problem: The Latent Semantic Analysis theory of the acquisition, induction, and representation of knowledge. Psychol. Rev. 25, 211-240 (1997). 528

J Lave, E Wenger, Situated learning: Legitimate peripheral participation (Cambridge University Press, Cambridge, England, 1991)

J Liedtka, T Ogilvie, Designing for growth: A design thinking toolkit for managers (Columbia University Press, New York, 2011)

A Liu, This is not a book: Transliteracies and long forms of digital attention (Paper presented at the Translittératies Conference, ENS Cachan, Paris, 2012). 7 Novementer 2012. Web: http://liu.english.ucsb.edu/this-is-not-a-book-longforms-of-shared-attention-in-thedigital-age-unbound-book-conference-amsterdam-the-hague/

N Manouselis, H Drachsler, K Verbert, E Duval, Recommender systems for learning (Springer, Boston, MA, 2012)

FT Marchese, E Banissi (eds.), Knowledge Visualization Currents: From Text to Art to Culture (Springer-Verlag, London, 2013)

R Martin, The opposable mind: Winning through integrative thinking (Harvard Business Press, Boston, 2009)

N Miyake, H Ishiguro, K Dautenhahn, T Nomura, Robots with children: Practices for human-robot symbiosis, in Proceedings of the $6^{\text {th }}$ International Conference of Human Robot Interaction, HRI 2011, ed. by A Billard, PH Kahn Jr, JA Adams, G Trafton (Lausanne, Switzerland, 2011). http://doi.acm.org/10.1145/1957656.1957659

PCM Molenaar, On the impossibility of acquiring more powerful structures: A neglected alternative. Hum. Dev. 29, 245-251 (1986)

H Muukkonen, K Hakkarainen, L Lipponen, T Leinonen, Computer support for knowledge building. Paper presented at 9th European Congress on Work and Organizational Psychology, Innovations for Work, Organization and Well-being (Espoo-Helsinki, Finland, May 1999), 1999

I Nonaka, H Takeuchi, The knowledge creating company (Oxford University Press, New York, 1995)

C Norris, E Soloway, Substantive Educational Change Is in the Palm of Our Children's Hands, in Handbook of Mobile Learning, ed. by Z Berge, L Muilenburg (Routledge, New York, NY, 2013)

J Oshima, R Oshima, Y Matsuzawa, Knowledge Building Discourse Explorer: A social network analysis application for knowledge building discourse. Educ. Technol. Res. Dev. 60, 903-921 (2012)

J Piaget, Psychology and epistemology: Towards a theory of knowledge (Viking Press, New York, NY, 1971)

M Resendes, Effect of formative feedback on enhancing ways of contributing to explanation-seeking dialogue in grade 2 (Paper presented at the Summer Institute on Knowledge Building, Puebla, Mexico, 2013). Web: www.kit.org/ SI2013-Papers/4803-Resendes.pdf

CP Rosé, YC Wang, Y Cui, J Arguello, K Stegmann, A Weinberger, F Fischer, Analyzing collaborative learning processes automatically: Exploiting the advances of computational linguistics in computer-supported collaborative learning Int. J. Comput. Supported. Collaborative. Learn. 3, 237-271 (2008)

G Salomon, T Globerson, Skill may not be enough: The role of mindfulness in learning and transfer. Int. J. Educ. Res, $11,623-638$ (1987)

M Scardamalia, Collective cognitive responsibility for the advancement of knowledge, in Liberal education in a knowledge society, ed. by B Smith (Open Court, Chicago, 2002), pp. 67-98 
M Scardamalia, Knowledge building environments: Extending the limits of the possible in education and knowledge work, in Encyclopedia of distributed learning, ed. by A DiStefano, KE Rudestam, R Silverman (Sage Publications, Thousand Oaks, CA, 2003), pp. 269-272

M Scardamalia, C Bereiter, Higher levels of agency for children in knowledge building: A challenge for the design of new knowledge media. J. Learn. Sci. 1(1), 37-68 (1991)

M Scardamalia, C Bereiter, Adaptation and understanding: A case for new cultures of schooling, in International perspectives on the design of technology-supported learning environments, ed. by S Vosniadou, E DeCorte, R Glaser, H Mandl (Lawrence Erlbaum Associates, Mahwah, NJ, 1996), pp. 149-163

M Scardamalia, C Bereiter, Knowledge building: Theory, pedagogy, and technology, in Cambridge handbook of the learning sciences, ed. by K Sawyer (Cambridge University Press, New York, 2006), pp. 97-118

M Scardamalia, C Bereiter, Education in an open informational world, in Emerging trends in the social and behaviora sciences, ed. by R Scott, S Kosslyn (Wiley Online Library, in press-aa)

M Scardamalia, C Bereiter, Knowledge building and knowledge creation: Theory, pedagogy, and technology, in Cambridge handbook of the learning sciences, ed. by K Sawyer, 2nd edn. (Cambridge University Press, New York, in press-bb)

M Scardamalia, C Bereiter, RS McLean, J Swallow, E Woodruff, Computer-supported intentional learning environments. J. Educ. Comput. Res. 5, 51-68 (1989)

M Scardamalia, C Bereiter, M Lamon, The CSILE project: Trying to bring the classroom into World 3, in Classroom lessons: Integrating cognitive theory and classroom practice, ed. by K McGilley (MIT Press, Cambridge, MA, 1994), pp. 201-228

M Scardamalia, J Bransford, R Kozma, E Quellmalz, New assessments and environments for knowledge building, in Assessment and Teaching of 21st Century Skills, ed. by P Griffin, B McGaw, E Care (Springer Science + Business Media B.V, New York, 2012), pp. 231-300

RC Schank, RP Abelson, Scripts, plans, goals, and understanding (Lawrence Erlbaum Associates, Hillsdale, NJ, 1977)

G Siemens, P Long, Penetrating the fog: Analytics in learning and education. EDUCAUSE Review 46(4), (2011). Available at: http://net.educause.edu/ir/library/pdf/erm1151.pdf

G Stahl, Group cognition: Computer support for building collaborative knowledge (MIT Press, Cambridge, MA, 2006)

SO Tergan, T Keller, Knowledge and information visualization: Searching for synergies (Springer Lecture Notes in Computer Science, Heidelberg / New York, in press)

P Thagard, Coherence in thought and action (MIT Press, Cambridge, MA, 2000)

P Thagard, Hot thought: Mechanisms and applications of emotional cognition (MIT Press, Cambridge, MA, 2006)

E Thelen, LB Smith, A dynamic systems approach to the development of cognition and action (MIT Press, Cambridge, MA, 1994)

S Toulmin, The uses of argument (Cambridge University Press, Cambridge, 1958)

H Tsoukas, A dialogical approach to the creation of new knowledge in organizations. Organ. Sci. 20, 941-957 (2009)

G von Krogh, K Ichijo, I Nonaka, Enabling knowledge creation: Unlocking the mystery of tacit knowledge (Oxford University Press, New York, 2000)

L Yuan, Will analytics transform education? A critical view on the data we gather about the learners, n.d. Web document: http://www.learningfrontiers.eu/?q=story/will-analytics-transform-education

doi:10.1186/s40561-014-0001-8

Cite this article as: Scardamalia and Bereiter: Smart technology for self-organizing processes. Smart Learning Environments 2014 1:1

\section{Submit your manuscript to a SpringerOpen ${ }^{\circ}$ journal and benefit from:}

- Convenient online submission

Rigorous peer review

- Immediate publication on acceptance

- Open access: articles freely available online

- High visibility within the field

- Retaining the copyright to your article

Submit your next manuscript at $\boldsymbol{\sim}$ springeropen.com 